\title{
Question analysis of mathematics textbook for 2013 curriculum and IB curriculum on quadratic equations
}

\author{
Aji Raditya*,1, Ratu Sarah Fauziah Iskandar ${ }^{1}$, Suwarno $^{2}$ \\ ${ }^{1}$ Universitas Muhammadiyah Tangerang, Indonesia \\ 2 Bina Nusantara University, Indonesia
}

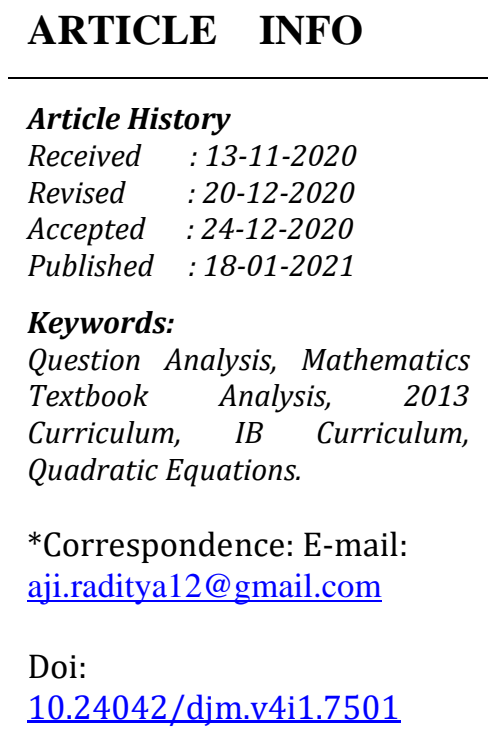

\begin{abstract}
The goal of this study is to compare the types of questions between the 2013 Curriculum Mathematics textbooks and the IB Curriculum on quadratic equations. The approach used in this research is a six-dimensional analysis method consisting of: mathematical activity, the difficulty level of the questions, the types of answers expected, the contextual situation, the types of responses, and the stages of the mathematical questions. The data collection technique is conducted by evaluating and explaining the types of questions. The types of questions were obtained from the 2013 Curriculum Mathematics textbook and the IB Curriculum based on a six-dimensional analysis, namely: mathematical activity, question complexity, type of answer, contextual situation, type of response, and mathematical questions. Based on the type, the results of this study show that the questions in the 2013 curriculum mathematics textbooks are more varied than the questions in the IB curriculum mathematics textbooks on the subject of quadratic equations. However, based on the number, there are more questions in the $I B$ curriculum mathematics textbook than the questions in the 2013 curriculum mathematics textbook.
\end{abstract}

http://ejournal.radenintan.ac.id/index.php/desimal/index

\section{INTRODUCTION}

Textbooks are one of the most important learning aids and are most often used in learning activities. Textbooks have also been known and used for a long time, especially in mathematics learning activities, the book The Element written by Euclid can be said to be one of the most widely used mathematics textbooks in the western world (Boyer \& Merzbach, 2011; Fan et al., 2013). Besides, it has been used for a long time as a textbook and is also an important tool. The textbook is expected to connect the curriculum used with daily learning activities in the classroom (Gracin, 2018; 
Özgeldi \& Esen, 2010). Yeap (2005) argues that mathematics textbooks play an important role in students' mathematical abilities, especially in Singapore (Yeap, 2005). Today's math textbooks have many features. One of the features of every mathematics textbook is sample questions and practice questions.

The question feature in the mathematics textbook is an important feature because the question feature is one way to see or understand the flow of students in learning mathematics. Besides, the question feature in the textbook provides students with opportunities to think conceptually, perform procedures, and encourage connections (Li, 2000; Özgeldi \& Esen, 2010). Especially in the current pandemic condition, when students cannot directly interact with teachers and peers to discuss, questions (both practice questions and sample questions) in textbooks can also be one of the tools in fostering student learning independence.

Research related to problem features in mathematics textbooks has been carried out by several researchers such as Li Y (2000) \& Gracin (2018). Li conducted research related to the comparison between mathematics textbooks in the United States and mathematics textbooks in China for the material of addition and subtraction of integers. In his research, Li uses a 3dimensional framework in carrying out the analysis, namely: Mathematical Features, Contextual Features, and Students' Mathematical Abilities needed to solve problems. Meanwhile, Gracin (2018) examines mathematics textbooks using a 5-dimensional framework. The 5dimensional framework is used to answer questions related to 1 ) The material that students learn in mathematics textbooks? 2) Mathematical abilities that students need to solve problems in mathematics textbooks? 3) Seeing the complexity of mathematical knowledge and activities that students need to solve problems in mathematics textbooks? 4) Types of answers to questions in mathematics textbooks? And 5) The context described in the problems in the mathematics textbook?

Quadratic equation material is part of the algebra material that students learn at the beginning of learning mathematics at the high school level. The quadratic equation is an important topic for students. In this topic, many abstract symbols must be interpreted into the daily context of students, so that students can solve real problems given which can be modeled as quadratic equations. On the other hand, Patricia (2019) said that there are still many misconceptions that cause errors in interpretation and modeling on the topic of quadratic equations. $98 \%$ of the factors that cause student errors are related to determining known information (Patricia, 2019). For example, it is an error to determine the values of $a, b$, and $c$ when you know that the quadratic function has the general form $f(x)=a x^{2}+b x+c$. Besides, another error is an error in applying the concept of the quadratic function to a given problem (especially in non-routine problems).

Research related to mathematics textbooks is still not widely conducted in Indonesia. Especially comparative research between mathematics textbooks with Indonesian curricula and curricula in other countries. This study focuses on the problem features displayed in mathematics textbooks, particularly in mathematics textbooks from the 2013 Curriculum and the IB Curriculum on the topic of quadratic equations.

\section{METHOD}

This research is qualitative research with the type of content analysis. The purpose of this study is to compare and describe the problems in the mathematics textbook for the 2013 curriculum and the IB curriculum. The data used in this study 
were all questions (sample questions and exercises) on the topic of quadratic equations. In the mathematics book from the 2013 Curriculum, the data is taken on the "Problem", "Exercise", "Example", "Competency Test" and "Project" features. Meanwhile, in the mathematics book from the IB Curriculum, data is taken from the features "Opening Problem", "Example", "Exercise","Investigation","Activity "and "Review Set". All questions in textbooks from Curriculum 2013 and Curriculum IB will be analyzed using the existing framework. Researchers will classify and encode the questions in the mathematics textbook. The framework used in this study is a six-dimensional analysis, consisting of mathematical activities, question complexity, types of answers, contextual situations, types of responses, and mathematical questions. The framework used in this study is a modification of the previous framework developed by Li (2000) and Gracin (2018). Table 1 shows the dimensions and subdimensions of the framework used and the coding techniques used in this study.

Tabel 1. Dimension and Sub-dimension

\begin{tabular}{|c|c|}
\hline Dimension & Sub-dimension \\
\hline Mathematical & Representing or modeling (A1) \\
\hline \multirow[t]{3}{*}{ Activity (A) } & Count or use various count operations (A2) \\
\hline & Interpretation (A3) \\
\hline & Give an argument or logical reason (A4) \\
\hline Problem complexity & Application of direct knowledge or basic skills (B1) \\
\hline \multirow{2}{*}{ (B) } & Making connections (B2) \\
\hline & Apply reflective knowledge (B3) \\
\hline \multirow{3}{*}{ Answer type (C) } & Closed Answer (C1) \\
\hline & Opened Answer (C2) \\
\hline & Multiple Choice Answers (C3) \\
\hline \multirow{3}{*}{$\begin{array}{l}\text { Contextual situation } \\
\text { (D) }\end{array}$} & Questions without context (D1) \\
\hline & Questions with the fiction context (D2) \\
\hline & Questions with real-world contexts (D3) \\
\hline \multirow[t]{3}{*}{ Response type (E) } & Numeric response (E1) \\
\hline & Mathematical expressions response (E2) \\
\hline & Response with answers and reasons (E3) \\
\hline Mathematical & Single Procedure (F1) \\
\hline Questions (F) & Layered Procedure (F2) \\
\hline
\end{tabular}

The coding of the questions was carried out by two researchers using the existing framework. The researcher performs the intra-reliability process between the researchers. In this activity, each researcher coded the existing questions. If there is a difference in the results of the code, the two researchers discuss the question until there is an agreement that the question falls into certain dimensions and sub-dimensions. The results of the activities were compared and analyzed for the intra-class correlation coefficient (ICC) values. This process aims to determine the reliability level of the coding that has been made. This activity resulted in a value of 0.92 . Based on this value, we can conclude that it has reliability "Very Good" according to the ICC value.

Table 2. ICC Values (Cicchetti, 1994)

\begin{tabular}{cc}
\hline Value & Reliability \\
$<0,04$ & Not Good \\
$0,04-0,59$ & Enough \\
$0,60-0,74$ & Good \\
$0,75-1$ & Excellent \\
\hline
\end{tabular}

RESULTS AND DISCUSSION 
Desimal, 4 (1), 2021 - 24

Aji Raditya, Ratu Sarah Fauziah Iskandar, Suwarno

In general, the results of this study indicate that in the mathematics textbooks of the two curricula there is no balance of question types, especially on the topic of quadratic equations.

Table 3. Research Result

\begin{tabular}{|c|c|c|c|c|c|c|}
\hline \multirow{3}{*}{$\begin{array}{l}\text { Dimension } \\
\text { Mathematical } \\
\text { activities (A) }\end{array}$} & \multirow{4}{*}{$\begin{array}{l}\qquad \text { Sub-dimension } \\
\text { Representing or modeling } \\
\text { Count or use various count operations } \\
\text { Interpreting }\end{array}$} & \multirow{2}{*}{$\begin{array}{c}\text { Code } \\
\text { A1 }\end{array}$} & \multicolumn{2}{|c|}{$\begin{array}{c}2013 \\
\text { Curriculum }\end{array}$} & \multicolumn{2}{|c|}{$\begin{array}{c}\text { IB } \\
\text { Curriculum }\end{array}$} \\
\hline & & & 31 & $47.69 \%$ & 222 & $41.73 \%$ \\
\hline & & A2 & 7 & $10.77 \%$ & 169 & $31.77 \%$ \\
\hline & & A3 & 21 & $32.31 \%$ & 123 & $23.12 \%$ \\
\hline \multirow{4}{*}{$\begin{array}{l}\text { Question } \\
\text { complexities } \\
\text { (B) }\end{array}$} & Provide logical arguments or reasons & A4 & 6 & $9.23 \%$ & 18 & $3.38 \%$ \\
\hline & $\begin{array}{l}\text { Direct application of knowledge or basic } \\
\text { skills }\end{array}$ & B1 & 12 & 18 & 195 & 36 \\
\hline & Establish or create a connection & B2 & 29 & $44.62 \%$ & 298 & $56.02 \%$ \\
\hline & Applying reflective knowledge & B3 & 24 & $36.92 \%$ & 39 & $7.33 \%$ \\
\hline \multirow{3}{*}{$\begin{array}{l}\text { Answer types } \\
\text { (C) }\end{array}$} & Closed answer & $\mathrm{C} 1$ & 57 & $87.69 \%$ & 502 & $94.36 \%$ \\
\hline & Opened answer & $\mathrm{C} 2$ & 8 & $12.31 \%$ & 13 & $2.44 \%$ \\
\hline & Multiple choice answers & C3 & 0 & $0.00 \%$ & 17 & $3.20 \%$ \\
\hline \multirow{3}{*}{$\begin{array}{l}\text { Contextual } \\
\text { situations (D) }\end{array}$} & Questions without context & D1 & 34 & $52.31 \%$ & 490 & $92.11 \%$ \\
\hline & Questions with fiction context & D2 & 6 & $9.23 \%$ & 18 & $3.38 \%$ \\
\hline & Questions with real-world context & D3 & 25 & $38.46 \%$ & 24 & $4.51 \%$ \\
\hline \multirow{3}{*}{$\begin{array}{l}\text { Response } \\
\text { types (E) }\end{array}$} & Numerical response & E1 & 38 & $58.46 \%$ & 465 & $87.41 \%$ \\
\hline & Mathematical expression response & E2 & 11 & $16.92 \%$ & 7 & $1.32 \%$ \\
\hline & Responses with reasons & E3 & 16 & $24.62 \%$ & 60 & $11.28 \%$ \\
\hline \multirow{2}{*}{$\begin{array}{l}\text { Mathematical } \\
\text { questions }(\mathrm{F})\end{array}$} & Single procedure & F1 & 17 & $26.15 \%$ & 370 & $69.55 \%$ \\
\hline & Layered procedure & F2 & 48 & $73.85 \%$ & 162 & $30.45 \%$ \\
\hline
\end{tabular}

Based on the dimension of mathematical activity (A), only a small part of the questions in the two textbooks are questions in the form of arguments or logical reasons. Besides, most of the questions are questions in the form of representing or modeling. Based on the question complexity dimension (B), the mathematics textbook problems in the two curricula still focus on constructing or making connections and have propositions or comparisons that are very different from other sub-dimensions. In the answer type dimension (C), the focus of the questions in the two textbooks analyzed is very dominant with questions with closed answer types. The percentage of questions with closed answers is very dominant compared to questions with open answers and questions with many answer choices. Based on the dimensions of the contextual situation (D), questions without context still dominate in the two books analyzed. In the dimension of response types (E), responses in numerical symbols are still more dominant than responses in the form of mathematical expressions or reasons.

In the dimension of mathematical questions (F), the two types of curriculum books have different focuses on each other. In the mathematics textbook of the 2013 curriculum, the percentage of questions that can be solved with layered procedures is more than the questions that can be solved with a single procedure. Meanwhile, the IB curriculum mathematics textbook applies the opposite. Based on the number of questions, there are 3192 questions in the mathematics textbook from the IB curriculum, while the mathematics textbook from the 2013 curriculum only has 390 questions for the topic of quadratic equations. Based on the number of questions available, the 2013 curriculum mathematics textbook has fewer questions than the mathematics textbook from the IB curriculum. However, the mathematics textbook from 
the 2013 curriculum had more variations of questions based on the dimensions analyzed compared to the mathematics textbook of the IB curriculum.

In the dimension of mathematical activity (A), based on the percentage of question types, the 2013 curriculum mathematics textbook is more spread out than in the IB curriculum mathematics textbook. But based on the number of questions available, the 2013 curriculum mathematics textbook is very small when compared to the number of questions in the IB curriculum mathematics textbook. Based on the results of the analysis, it can be seen that both the 2013 curriculum mathematics textbook and the IB curriculum have more questions with the type of representing and modeling (subdimension A1) than the questions in other subdimension $A$. Based on the percentage, $47.69 \%$ of the questions in the 2013 curriculum textbook were questions of type A1 compared to the IB curriculum textbook which was only $41.73 \%$. However, based on the number of questions, there were only 31 types of questions in the 2013 curriculum mathematics textbook, while in the mathematics textbook of the IB curriculum, there were 222 questions.

In the question complexity dimension (B), in general, the questions in the mathematics textbook in the 2013 curriculum have a more even distribution than the questions in the mathematics textbook in the IB curriculum. Furthermore, the results of the analysis obtained were both mathematics textbooks in the 2013 curriculum and the IB curriculum, both of which had a proportion of $44.62 \%$ and $56.02 \%$ for the types of problems to build or make connections (B2). However, based on the number of questions, there were only 29 questions with type B2 in the mathematics textbook in the 2013 curriculum compared to the questions of the same type in the mathematics textbook in the IB curriculum which reached 298 questions. The interesting thing is seen in the smallest number of question types in the $\mathrm{B}$ dimension, in the mathematics textbook in the 2013 curriculum, the B1 question type has the least number of questions compared to the B2 and B3 question types with only 12 questions or $18.46 \%$ of the total questions. Meanwhile, in the mathematics textbook in the IB curriculum, the B3 question type had the least number of questions compared to other types of questions with only 39 questions or $7.33 \%$ of the total number of questions. 
Desimal, 4 (1), 2021 - 26

Aji Raditya, Ratu Sarah Fauziah Iskandar, Suwarno
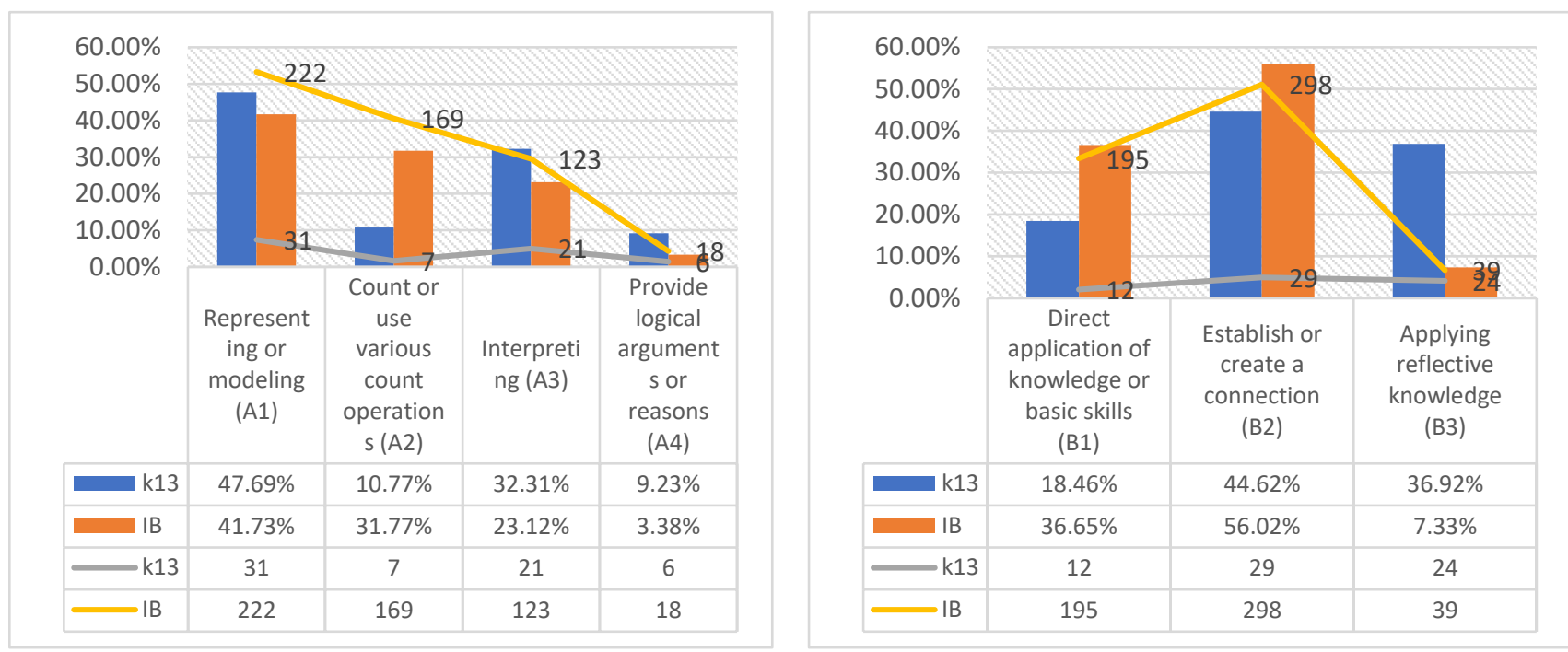

Figure 1. Percentage of Mathematical Activity Dimensions (A) and Question Complexity (B).

Based on the type of answer (C), the two mathematics textbooks analyzed were still very focused on the type of questions with closed answers (C1) which accounted for more than $85 \%$ of the number of questions analyzed. Whereas the type of questions with open answers (C2) in the mathematics textbook in the 2013 curriculum was only 8 questions or $12.31 \%$ of the total questions and in the mathematics textbook in the IB

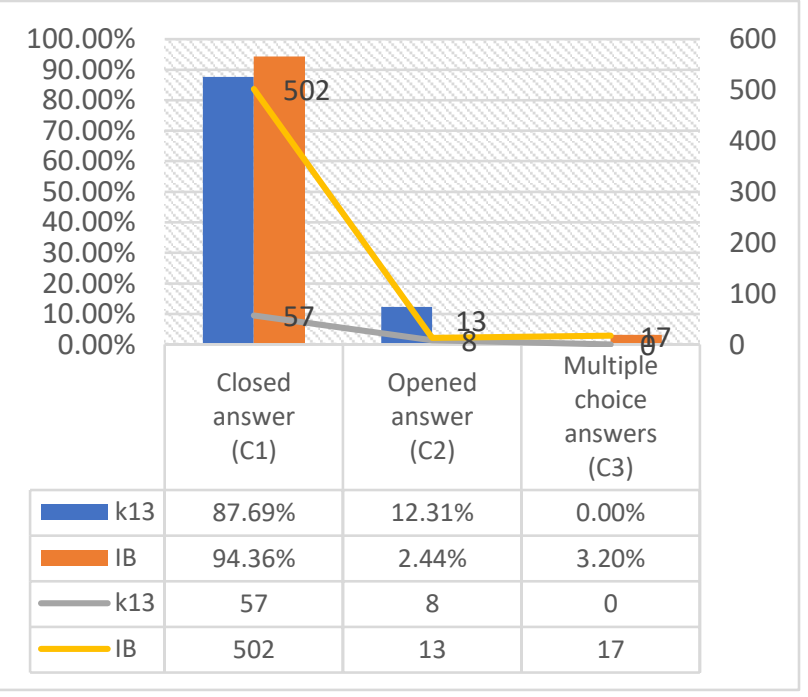

curriculum there were only 13 questions or $2.44 \%$ of the total existing questions.

Whereas in the contextual situation dimension (D), the two mathematics textbooks still focus on questions without context (D1) but in the 2013 curriculum textbook the proportions of D1, D2 and D3 are better than the mathematics textbooks in the IB curriculum which have a higher proportion. of $92 \%$ for the type of question without context (D1) while for D2 and D3 each it was less than 5\%.

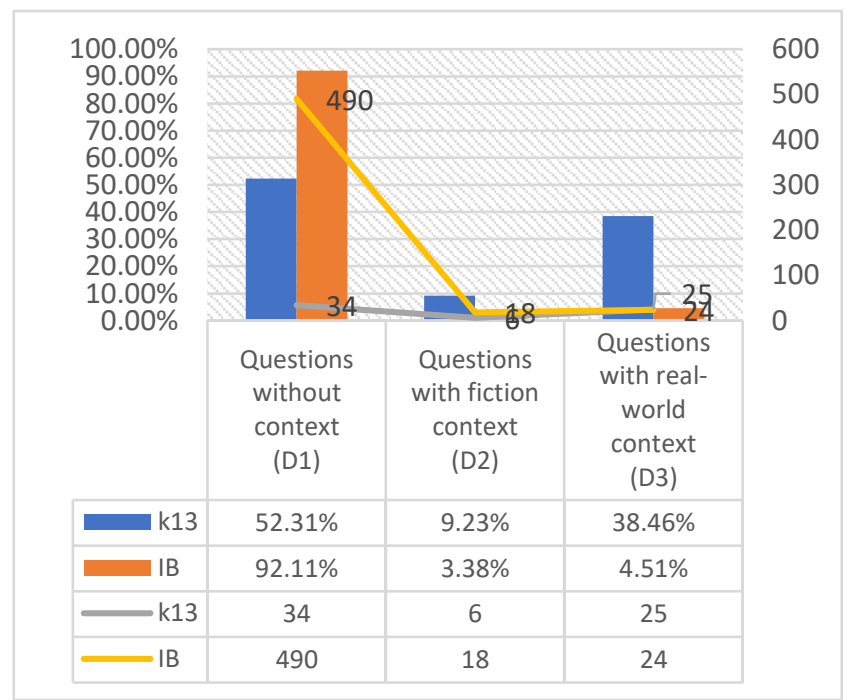

Figure 2. Percentage of Answer Type Dimensions (C) and Contextual Situations (D)

Based on the type of response (E), both of them still focus on the types of questions that only expect answers without reasons or arguments (E1) as 
many as $58.46 \%$ in the 2013 curriculum and $87.41 \%$ in the IB curriculum, compared to the types of questions that expect answers and reasons ( E3) or any type of question that only expects a reason (E2). Meanwhile, based on the mathematical question (F), both have conflicting results. In the mathematics textbook in the 2013 curriculum,

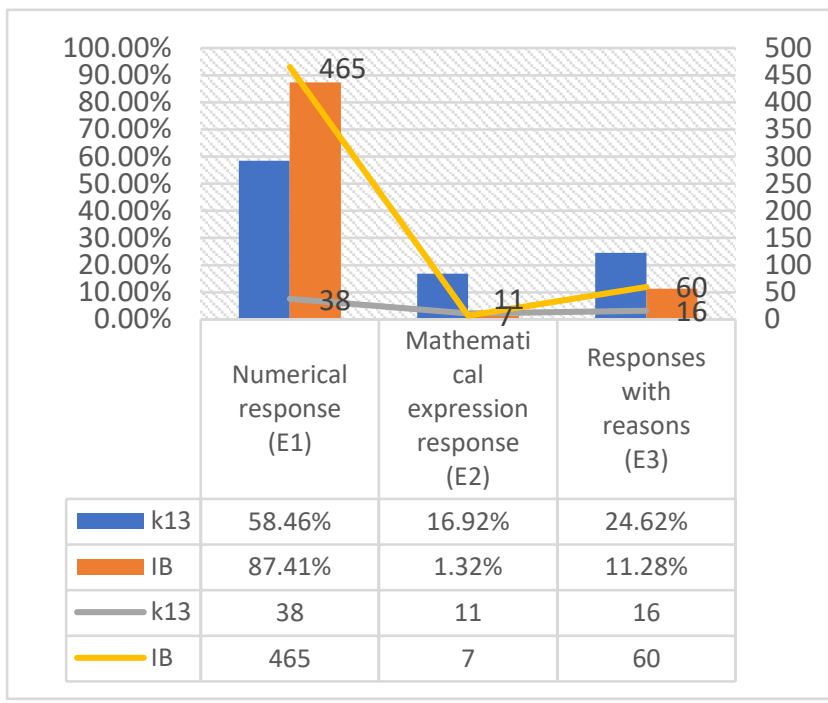

questions with layered procedures (F2) were more dominant $(73.85 \%)$ compared to questions that only used single procedures (F1) of 26.15\%. Meanwhile, mathematics textbooks in the IB curriculum, questions with single procedures are more dominant than questions that have layered procedures.

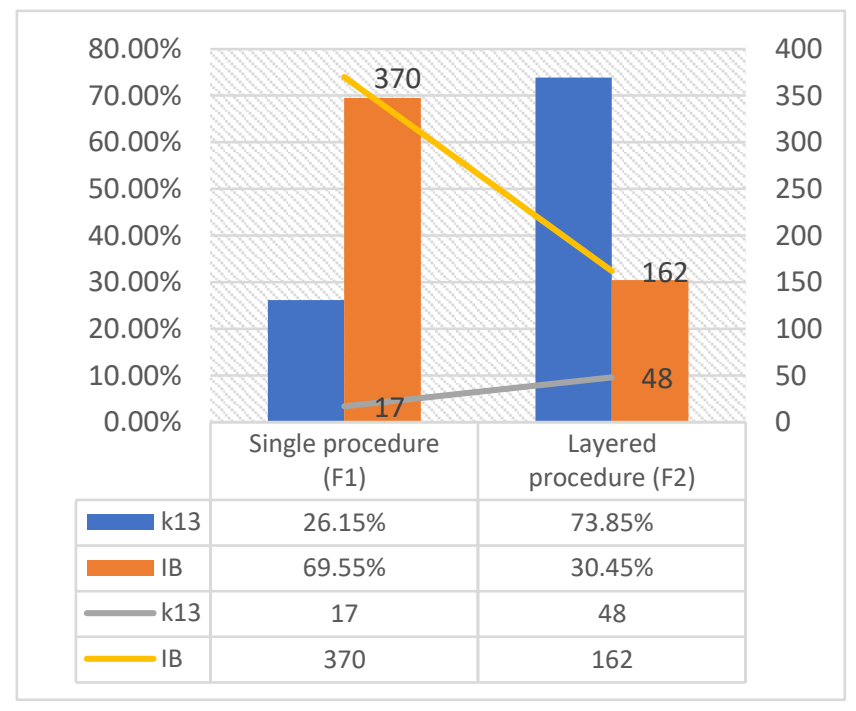

Figure 3. Percentage of Response Type Dimensions (E) and Mathematical Questions (F)

Based on the data above, in general, the variation of questions in the mathematics textbook from the 2013 curriculum is better than the mathematics textbook in the IB curriculum. This is indicated by a fairly balanced percentage for mathematics textbooks in the 2013 curriculum in each dimension compared to the percentage for each dimension of mathematics textbooks in the IB curriculum. But based on the quantity, the questions in the mathematics textbook from the IB curriculum were 3192 questions compared to the questions in the mathematics textbook in the 2013 curriculum which were only 390 questions for the topic of quadratic equations. The very basic difference between these two books is in the dimension of mathematical questions (F), mathematics textbooks in the 2013 curriculum are dominated by questions with layered procedures (as much as 73, $85 \%$ ) while mathematics textbooks in the IB curriculum are dominated by questions with single procedures (as much as 69.55\%). On another dimension, both the mathematics textbooks in the 2013 curriculum and the IB curriculum can be concluded that they have the same tendency, such as the existing questions still focus on questions without context (both mathematical context and everyday context) which require closed answers and no explanation (answers only). This is very disappointing, especially during a pandemic like this, where teacher-student interactions are very limited, so one of the easiest ways for students to learn mathematics is to use mathematics textbooks. But based on the research conducted, existing mathematics textbooks only have types of questions that are without context, require closed 
answers, and without reason. Based on Hollebrand \& Amaral (2017) and Kurniawan, Putri \& Hartono (2018), questions that have context (especially everyday context) and are open-ended have the potential to help students develop their ability to interpret problems and train students become good problem solvers and have the potential to develop their mathematical abilities (Barcelos Amaral \& Hollebrands, 2017; Kurniawan et al., 2018).

\section{CONCLUSIONS AND SUGGESTIONS}

Based on the data above, in general, the variation of questions in the mathematics textbook in curriculum 13 is better than the mathematics textbook in the IB curriculum. This is indicated by a fairly balanced percentage for mathematics textbook curriculum 13 in each dimension compared to the percentage of each dimension in the IB curriculum mathematics textbook. But based on the quantity, the questions in the 2013 curriculum mathematics textbook are far less than the questions in the IB curriculum mathematics textbook for the subject of quadratic equations.

\section{REFERENCES}

Barcelos Amaral, R., \& Hollebrands, K. (2017). An analysis of context-based similarity tasks in textbooks from Brazil and the United States. International Journal of Mathematical Education in Science and Technology, 48(8), 1166-1184. https://doi.org/10.1080/0020739X. 2017.1315188

Boyer, C. B., \& Merzbach, U. C. (2011). A history of mathematics (3rd ed.). John Wiley \& Sons.

Cicchetti, D. V. (1994). Guidelines, criteria, and rules of thumb for evaluating normed and standardized assessment instruments in psychology. Psychological Assessment,
6(4), 284

Fan, L., Zhu, Y., \& Miao, Z. (2013). Textbook research in mathematics education: development status and directions. ZDM, 45(5), 633-646.

Gracin, D. G. (2018). Requirements in mathematics textbooks: a fivedimensional analysis of textbook exercises and examples. International Journal of Mathematical Education in Science and Technology, 49(7), 10031024.

Kurniawan, H., Putri, R. I. I., \& Hartono, Y. (2018). Developing open-ended questions for surface area and volume of beam. Journal on Mathematics Education, 9(1), 157168.

https://doi.org/10.22342/jme.9.1.46 40.157-168

Li, Y. (2000). A comparison of problems that follow selected content presentations in American and Chinese mathematics textbooks. Journal for Research in Mathematics Education, 31(2), 239-241. https://doi.org/10.2307/749754

Özgeldi, M., \& Esen, Y. (2010). Analysis of mathematical tasks in Turkish elementary school mathematics textbooks. Procedia - Social and Behavioral Sciences, 2(2), 2277-2281. https://doi.org/10.1016/j.sbspro.20 10.03 .322

Patricia, F. A. (2019). Analisis kesalahan mahasiswa dalam menyelesaikan persamaan kuadrat pada mata kuliah aljabar elementer. PRISMATIKA: Jurnal Pendidikan Dan Riset Matematika, 1(2), 8-15. https://doi.org/10.33503/prismatik a.v1i2.430

Yeap, B. H. (2005). Building foundations and developing creativity: An analysis of Singapore mathematics textbooks. Third East Asia Regional Conference on Mathematics Education in Shanghai, China. 